\title{
Rice-straw based cement brick microclimatic thermal impact assessment in Cairo, Egypt
}

\author{
Tamer Akmal ${ }^{1}$, Mohammad Fahmy ${ }^{2,}$, Abdul-Wahab El-Kadi ${ }^{3}$ \\ ${ }^{1}$ Department of Architecture, Faculty of Engineering, Misr International University, Cairo, Egypt \\ ${ }^{2}$ Department of Architecture, Military Technical Collage, Cairo, Egypt \\ ${ }^{3}$ Department of Architecture, Al-Skerouk Higher Institute of Engineering, Al-Sherouk Academy, Cairo, Egypt \\ *Corresponding author. Tel: + (202)2 4029 382, Fax: + (202)2 2621 908, E-mail: md.fahmy@live.com
}

\begin{abstract}
The population and urbanization growth will lead to more dependency on mechanical cooling which is not a long term sustainable strategy. Therefore, it is important to ensure all elements involved in urban sustainable developments are well performing. Of these elements, building materials have an essential role to adjusting outdoor heat environment transfer to the indoors. As part of the research society work in Cairo towards minimizing the "black cloud" generated due to burning rice roots and straw after cultivation, this paper studies the thermal performance of a novel manufactured brick using rice straw fibbers on a cement-aggregate mixture basis. It has been designed to provide a recycled constructional biomaterial, to help healthy urban environment and reduce cooling energy demands. ENVI-met BETA5 numerical simulations were held for an existing microclimatic area to assess the impact of this brick on outdoor comfort in terms of Predicted Mean Vote, PMV, as well as for indoor conditions in terms of ambient air temperature. Among the many mixtures to produce the least bricks number suitable for transportation (1000 bricks), only two were optimum for cost, mechanical and thermal properties. In comparison with normal cement brick, PMV records showed fixed values using the selected rice-straw based cement brick mixture. In evening, it recorded less mean outdoor air temperature as different wall heat interaction occurred due to the new brick k-value. This suggests that the new brick balances between indoor and outdoor needs and contributes to further investigations in terms of energy conscious urban planning.
\end{abstract}

Keywords: Rice-straw cement brick, thermal impact assessment.

\section{Introduction}

Cooling energy consumption increase due to climate change [1-5] and due to unsustainable urban developments [6-8] has motivated research society in Egypt towards urban planning applied solutions by urban form design [9-12]. And despite the initiative building construction energy code [13] to legislate energy saving conscious materials for single building, there still no consideration for the recycled materials and biomaterials specially with regard to the large urban development movements around major cities of Egypt. From this standing point, rice crop is considered one of the major agriculture products in the world and in Egypt as a food supplementary as well as many by-products using its remnants and residuals after cultivation. Agriculture by-products are acknowledged as biomass energy source [14], as low cost building materials [15] and as reinforcing materials [16], whereas all these approaches stand as recycling strategies to reduce environmental impacts such as increase of $\mathrm{CO}_{2}$ emissions $[15,17]$.

Rice-straw based brick is one of the agriculture by-products internationally acknowledged such as through the development of either clay sand or cement mixtures with rice-straw [18]. In India, [19] presented the rice-straw based cement panel but didn't consider the commercial sizes of brick, or its thermal properties on a neighborhood scale which is considered a local scale from a climatology point of view.

In Egypt what is so called a black cloud is basically attributed to two reasons; burning the remnants of rice straw and the brick industrial pollution. Rice straw residuals per year is around 3.5 million tons, of which about $1.5 \mathrm{million}$ tons is used in production of organic 
fertilizers, to be used with storage of some crops (onions - potatoes), plantation of nontraditional crops (mushrooms) and to feed farm animals instead of hay [20].

A wasted amount 2: 2.5 tons per year of rice straw are disposed of burning which has a big share in the formation of the black cloud specially in southern delta governorates and almost whole Greater Cairo specially in winter when humidity settles the suspended smog [19] which causes a serious health problem. The ministry of state for environmental affairs, MSEA, in cooperation with many sectors started establishing factories in delta for composting and converting rice-straw to other forms such as untraditional fertilizers, thermal gas and bio fuels but a recycling towards involvement in construction industry such as low-cost housing materials hasn't been approached yet [17].

\section{Methodology}

The main objective of the research is to preserve the environment benefit from rice straw recycling so that a low cost building material is produced and sustainable implications on a neighborhood scale can be achieved in terms of energy saving and thermal comfort. The Egyptian standards for the concrete work was the base of the brick sample and then some differentiations in the components were done [21,22].

\subsection{Field work}

The starting blend idea was the addition ratio of rice straw to mix the concrete bricks to replace the aggregates (Haswa) part as filler and for non-loaded bearing brick to achieve less dense as possible to save the cost of the structure of the building, less cost as possible to achieve an economic retrofit, and enough coherent brick for the trading and handling with minimum damage. Research was conducted with more than 250 different mixtures divided into three main groups based on the ratios of sand to aggregates of $2: 1,4: 3$ and 1:1 with varying amounts of rice straw and cement in kilograms with each ratio as fiber filler, fig. 1 . A mixture without using aggregates to reduce the weight and increase the amount of straw was also prepared. The parameters of the density-price were initially compared with its corresponding normal cement bricks $\left(1880: 1720 \mathrm{Kg} / \mathrm{m}^{3}\right)$ manufactured by the National Company of Cement and then on a local scale thermal performance basis to assess their impacts on the pedestrian comfort as well as on the ambient air temperature which is associated with specific indoor climate conditions, comfort, cooling energy demand and green house gases emissions.
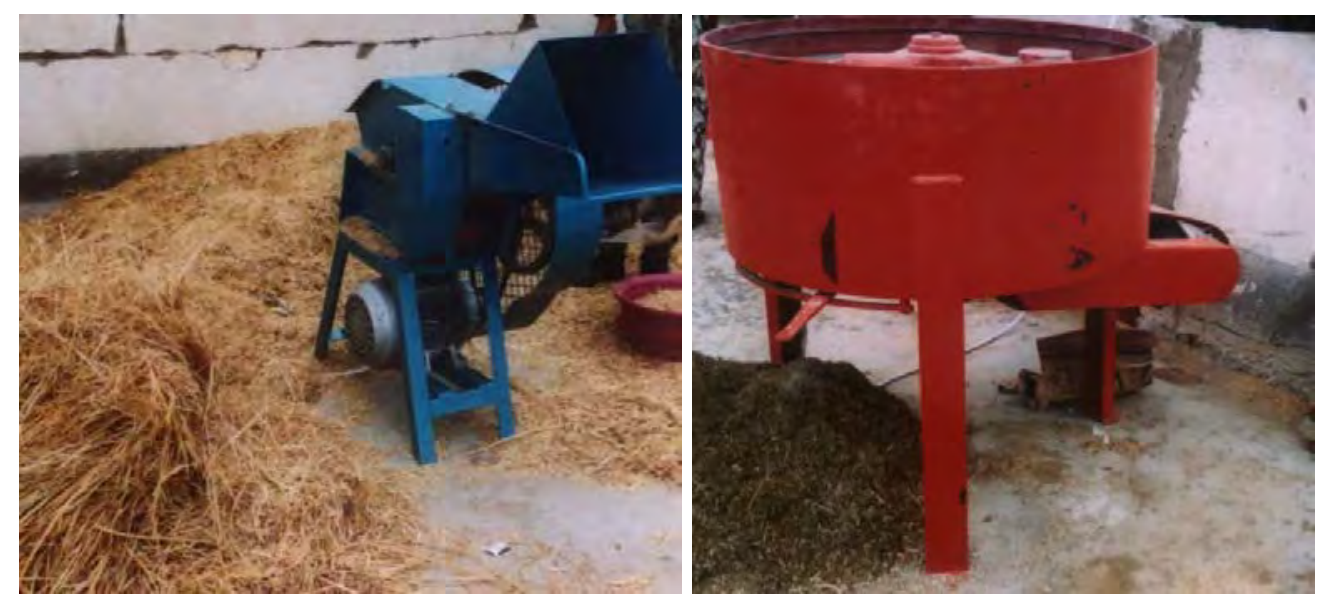

Fig. 1: Instrumentations used to prepare the different mixtures’ samples. 


\subsection{Measuring brick properties}

In order to assure the strength of each brick sample from each mixture, solid and hollow bricks were produced for the common size $25 \times 12 \times 13 \mathrm{~cm}$, fig. 2 . The first set of samples were manufactured on the basis of $4 \mathrm{~cm} 3$ aggregate $+4 \mathrm{~cm} 3$ Sand $+\mathrm{s}$ traw $+\mathrm{C}$ ement. By gradually increasing the amount of straw to a range of mixtures ranging from $2 \mathrm{~kg}$ to $7 \mathrm{~kg}$ straw for the same mixture with the change in the percentage of cement added to the mixture from 10: 30 ki lograms cement as the volume of the mixture increases with the amount of straw added. Samples with the first increase in the proportion of straw had been inconsistent, even with the increase in the proportion of cement; therefore, according to the mechanical pressure test, other groups of samples have been fixed of sand to aggregate to be 4:3,2:1 and new 15 samples designed to produce only solid brick with a size of $25 \times 12 \times 6 \mathrm{~cm}$. The most successful mixtures with respect to cost were of the brick blend no. 1 and no. 4 as fig. 2 and table 1 indicate. Measures were done for samples in the Housing and Building Research Centre in Cairo and in the main laboratories of Major Projects Corp of the Egyptian Armed forces. Results of measure show that all samples of both solid and hollow bricks don't have any color change due to chemical salts' residuals from hydration process. Water absorption factor varied from $4-21 \%$ of the brick weight for $25 \times 12 \times 13 \mathrm{~cm}, 25 \times 12 \times 6 \mathrm{~cm}$ and $25 \times 12$ $\times 13 \mathrm{~cm}$ solid, solid, hollow bricks respectively. Adding coloring powders didn't affect any of the mechanical or physical properties of any sample. The most important factor was the brick breaking stress which was best for the mixtures no. 1 and 4 as highlighted in table 1. Samples of each brick mixture have been produces for measurements and analysis purposes with ratios of sand : aggregates and by increasing the amounts of cement and rice-straw in 15 steps, table 1. To produce (1000) bricks of both these two bricks, unlike the samples components amounts produced just for measurements, amount of materials of the brick mixture were for mix. no. $1 ; 8.5 \mathrm{~cm}^{3}$ sand, $8.5 \mathrm{~cm}^{3}$ aggregate, $42 \mathrm{~kg}$ straw, $180 \mathrm{~kg}$ cement and its properties for the less cost of $46.8 \mathrm{EGP}$ were $1545 \mathrm{~kg} / \mathrm{m} 3$ density, and $18.7 \mathrm{~kg} / \mathrm{m}^{2}$ stress. Mix. no. $4 \mathrm{w}$ as $8.0 \mathrm{~cm}^{3}$ sand, no aggregate, $100 \mathrm{~kg}$ straw, $350 \mathrm{~kg}$ cement and its properties for the less cost of $48.4 \mathrm{EGP}$ were $884 \mathrm{~kg} / \mathrm{m}^{3}$ density, and $4.4 \mathrm{~kg} / \mathrm{m}^{2}$ stress. The later mixture had to have a compression of about $15 \%$ of its height due to the more straw. Cost (on 2005) was calculated according to about $270 \mathrm{EGP} /$ tone cement, $10 \mathrm{EGP} / \mathrm{m}^{3}$ of Sand, $25 \mathrm{EGP} / \mathrm{m}^{3}$ of aggregate 50 $\mathrm{EGP} /$ tone of rice straw and $80 \mathrm{EGP} /$ tone of stone powder. Despite brick stress varied between $4-20 \mathrm{~kg} / \mathrm{m}^{2}$ which is not compared with the stress of the brick used as bearing walls, but this brick is designed for non-loaded walls usage.
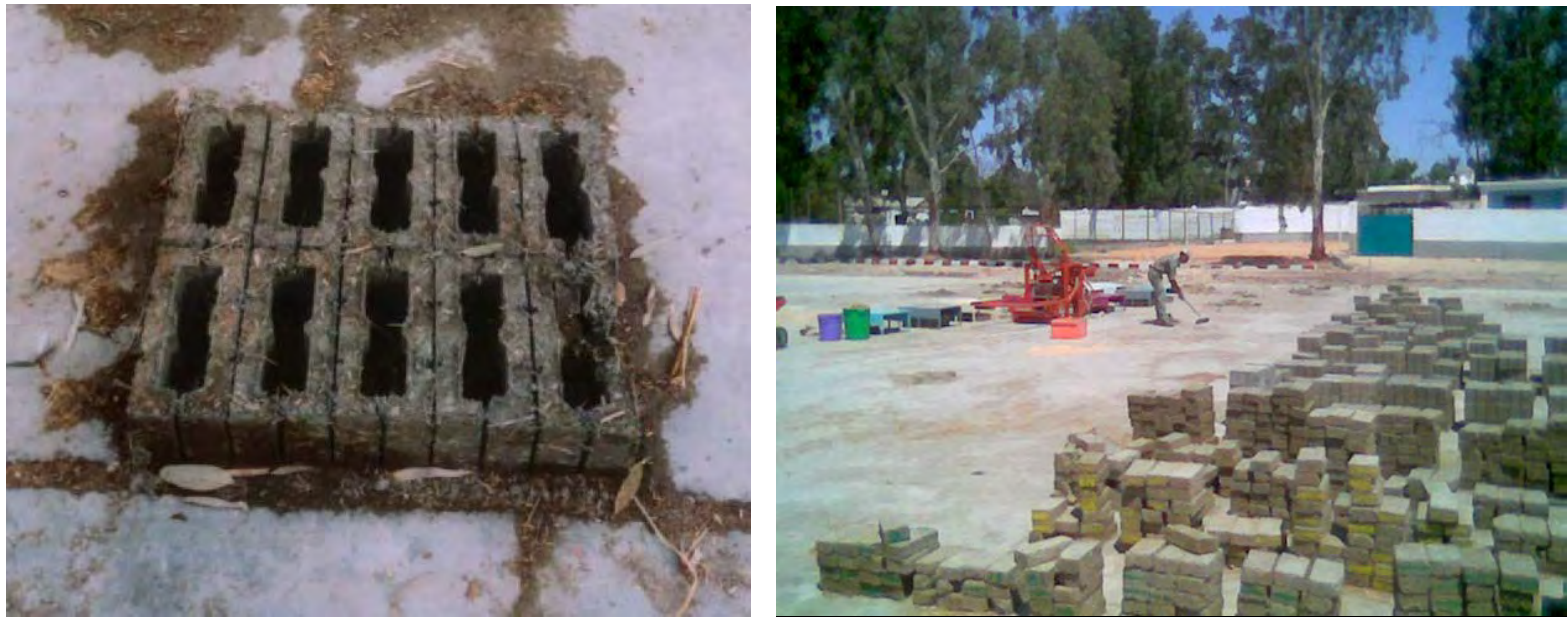

Fig. 2: Unsuccessful hollow and successful solid rice-straw based brick. 


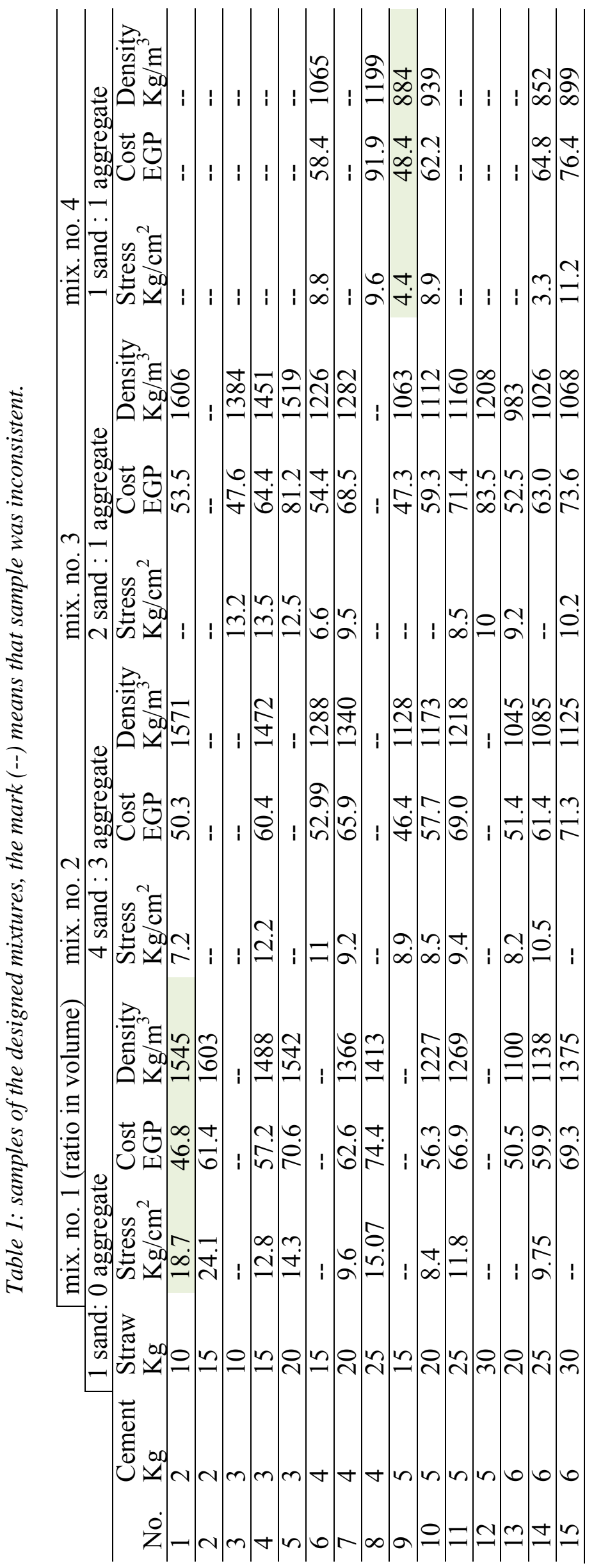




\subsection{Numerical simulation:}

As the main idea of this paper is to study how biomaterial such as rice-straw based cement brick can modify outdoor-indoor climate in terms of pedestrian comfort and outdoor air temperature $\mathrm{T}_{\mathrm{a}}$, ENVI-met BETA5 urban climate numerical package has been used. Numerical simulations were held to easily simulate neighborhood complexities to help providing design and planning decision support [23]. ENVI-met [24] is a three-dimensional numerical model that can simulate the surface-plant-air interactions of urban environments with a typical resolution of 0.5 to $10 \mathrm{~m}$ in space from a single building up to neighborhood. It is CFD based but with much improvements than only a package for fluid dynamics' simulations [25]. Simulations using the k-value of the rice-straw based cement brick in comparison with normal cement brick were applied on the $1^{\text {st }}$ of July which is the extreme summer hot day analyzed by ECOTECT2010 [26].

Table 2 show the data input for simulations for brick mixture no. 4 which has the less density and hence the less k-value. Nevertheless, first parameter assessed is the PMV at $1.2 \mathrm{~m}$ above ground level to represent outdoor conditions modifications in terms of pedestrian comfort. Second is the ambient temperature $\mathrm{T}_{\mathrm{a}}$ also at $1.2 \mathrm{~m}$ above ground level to represent the site air temperature modified after the new brick which gives impression about reductions of indoor cooling demand in comparison of that of using normal cement brick. For these purposes, a case study in Cairo, latitude of $30^{\circ} 7^{\prime} \mathrm{N}$ and longitude of $31^{\circ} 23^{\prime} \mathrm{E}$, is a semi-arid mid-latitude climate zone [27], is examined. The case study is part of the Fifth community which is built in late $20^{\text {th }}$ century, as one of New Cairo communities. It lies to the east of the $1^{\text {st }}$ Greater Cairo's ring road, fig. 3.

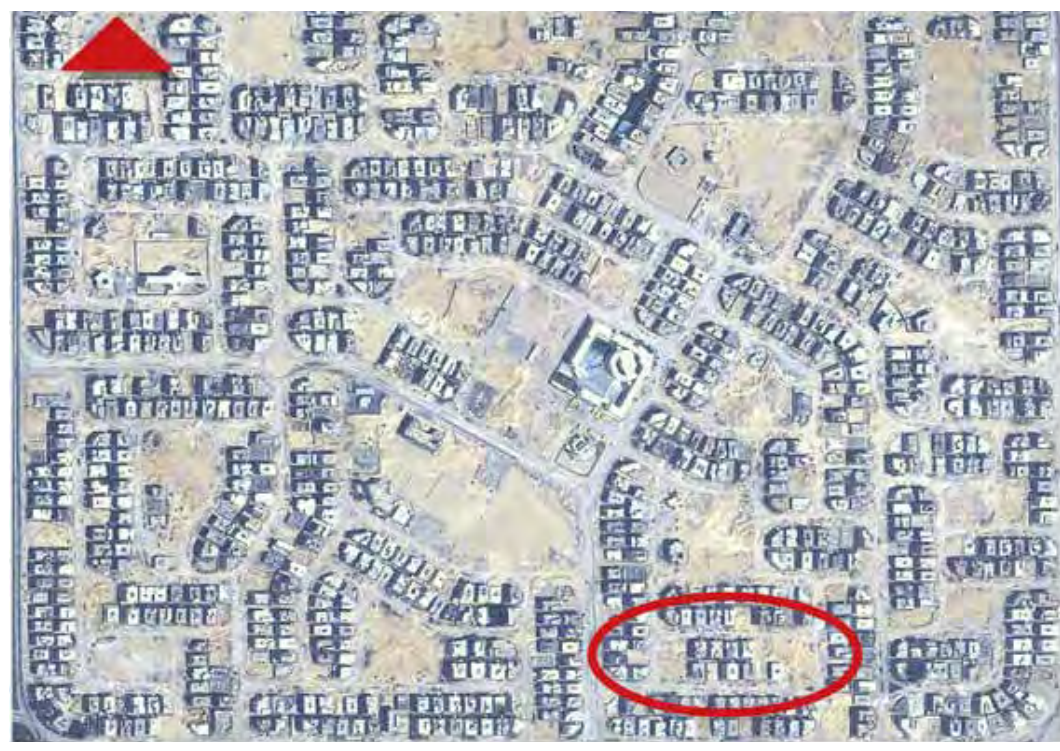

Fig. 3: Location of the case study area on the layout of the neighbourhood located in New Cairo.

Table.2: Inputs used in simulations for both rice-straw and normal cement brick [13, 24, 28].

\begin{tabular}{lll}
\hline No. & Parameter & Value \\
\hline 1 & Ta & $301.95^{\circ} \mathrm{K}$ \\
2 & $R H$ & $59 \%$ \\
3 & $V$ & $3.5 \mathrm{~m} / \mathrm{s}$ at $10 \mathrm{~m}$ height \\
4 & k-value Walls & 0.41 and 1.25 watt $/ \mathrm{m} . \mathrm{K}$ for rice-straw and normal cement \\
& & brick respectively \\
6 & Albedo Walls & 0.25 \\
8 & Human walking speed & $1.1 \mathrm{~m} / \mathrm{s}$ \\
9 & Pedestrian Clo. & 0.50 \\
\hline
\end{tabular}




\section{Results implications}

Basically, as ENVI-met model considers the fabric as heat sink for the outdoor environment, a heat exchange should have generated the shift in air temperature as shown if fig. 4. A ir temperature using the normal cement brick $\mathrm{T}_{\mathrm{n}}$ is less than its corresponding of the Rice-Straw based brick by about $0.1{ }^{\circ} \mathrm{C}$ early simulation time and the opposite at evening time.

Outdoor temperature was less than indoors attributed to the less k-value of the Rice-straw brick of 0.41 which intercept more outdoor heat compared with $1.25 \mathrm{k}$-value for the normal cement brick. This clarifies why pedestrian comfort in terms of PMV hasn't any change in its values which can be attributed to the holistic nature of PMV as it considers all environmental and personal aspects which haven't been changed except the air temperature, therefore there was no need to add PMV figure. Just to mention not to list these factors affecting PMV; the outdoor radiation environment and the walls reflectivity factor stayed fixed in both simulations and in turn PMV stayed as it is using both the thermal conductivity k-values for of both brick types.

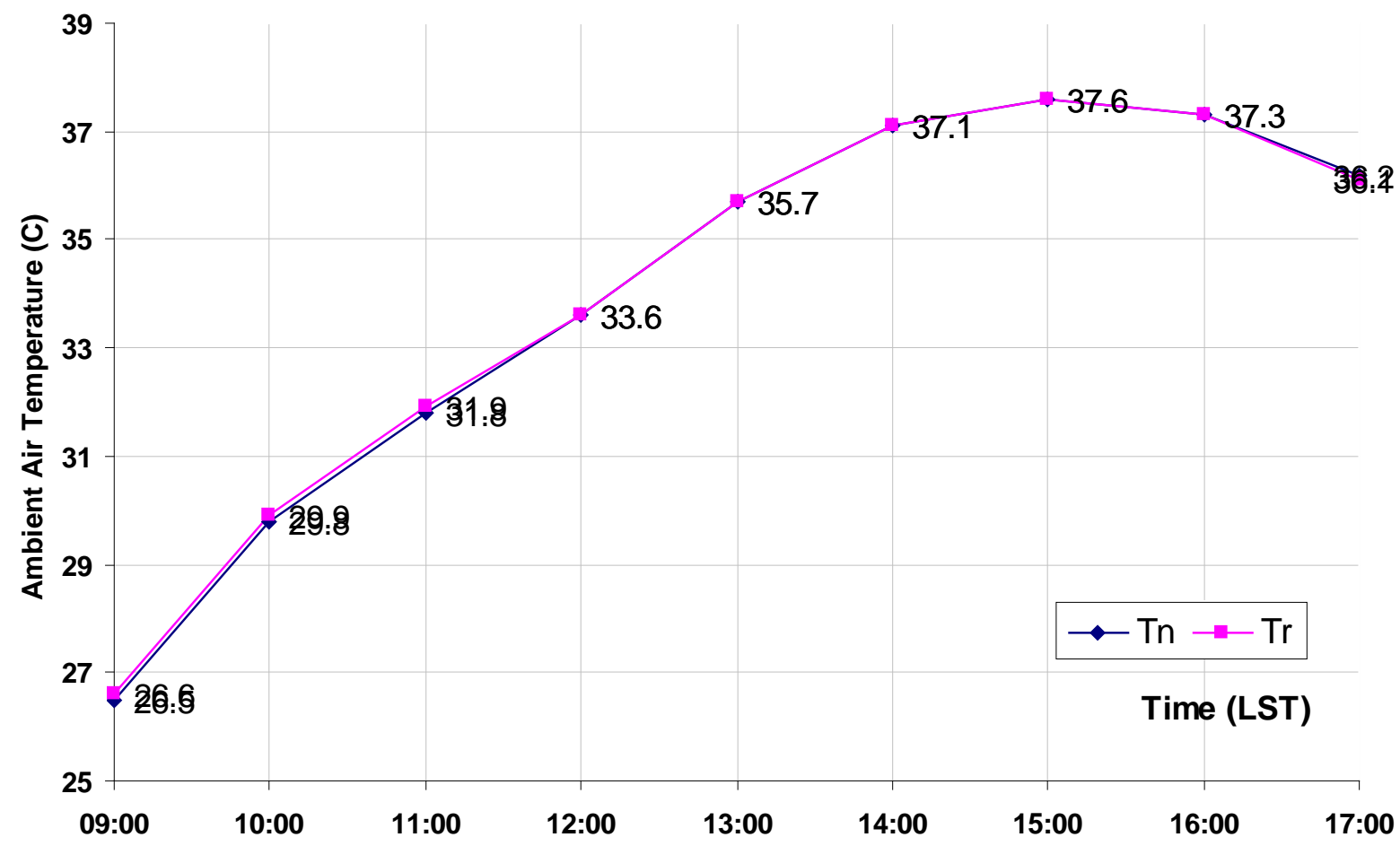

Fig. 4.

\section{Discussion and conclusion}

Studied in this paper, a new brick type based on the recycled rice-straw was innovated. The rice-straw has replaced part of the aggregates used in the normal cement brick by the try and error to generate a stable blend after which mechanical and thermal experiments have been conducted. Among the many mixtures examined, both mixtures highlighted in table 1 were only the stable but the mixture of $1 \mathrm{~s}$ and: 0 aggregate with $2 \mathrm{~kg}$ cement and $10 \mathrm{~s}$ traw and a pressure of 0.15 from the brick height, was the most efficient in terms of cost. Eventually, to examine its environmental thermal impact, ENVI-met BETA5 numerical simulations were held to generate pedestrian comfort levels and ambient air temperature.

The fist parameter hasn't been changed due to the fixation of the many environmental and personal factors affecting PMV. The later parameter showed promising changes and in turn a 
promising energy savings in the cooling demand especially with respect to the time simulations were held in at which electricity used in mechanical cooling in Egypt suffers many cut off. Moreover, this recycled bio-brick not only helps in decreasing air pollution, but also reduces construction cost and indicate a maximized cost reductions if added to energy reductions. However, further simulations can be on larger scales and different cases' climate conditions to ensure quantitevily such numerical simulation findings in this work.

\section{References}

[1] Radhi, H., A comparison of the accuracy of building energy analysis in Bahrain using data from different weather periods. Renewable Energy, 2009. 34(3): p. 869-875.

[2] McEVOY, D., Climate Change and Cities. Built Environment, 2007. 33(1): p. 5-9.

[3] Rosenfeld, A.H., H. Akbari, S. Bretz, B.L. Fishman, D.M. Kurn, D. Sailor, and H. Taha, Mitigation of urban heat islands: materials, utility programs, updates. Energy and Buildings, 1995. 22(3): p. 255-265.

[4] Wilby, R.L., A Review of Climate Change Impacts on the Built Environment. Built Environment, 2007. 33(1): p. 31-45.

[5] Levermore, G.J., A review of the IPCC Assessment Report Four, Part 1: the IPCC process and greenhouse gas emission trends from buildings worldwide. Building Service Engineering, 2008. 29(4): p. 349-361.

[6] El Araby, M., Urban growth and environmental degradation. The case of Cairo, Egypt. Cities, 2002. 18(3): p. 135-149.

[7] Fahmi, W. and K. Sutton, Greater Cairo's housing crisis: Contested spaces from inner city areas to new communities. Cities, 2008. 25(5): p. 277-297.

[8] Sutton, K. and W. Fahmi, Cairo's urban growth and strategic master plans in the light of Egypt's 1996 population census results. Cities, 2001. 18(3): p. 135-149.

[9] Fahmy, M., Interactive urban form design of local climate scale in hot semi-arid zone, in School of Architecture. 2010, University of Sheffield: Sheffield.

[10]Fahmy, M. and S. Sharples, On the development of an urban passive thermal comfort system in Cairo, Egypt. Building and Environment, 2009a. 44(9): p. 1907-1916.

[11]Fahmy, M., Urban form adaptation towards minimizing climate change effects in Cairo, Egypt., in Accepted abstract and submitted Manuscript to Building Sustainability in the Arabic Region. 2010, HBRC, Housing and Building Research Centre: Cairo.

[12]Fahmy, M., A. Trabolsi, and S. Sharples, Dual stage simulations to study microclimate thermal effect on comfort levels in a multi family residential building., in 11th International Building Performance Simulation Association Conference 2009: University of Strathclyde in Glasgow, 27-30 July.

[13]HBRC, Energy Efficiency Residentail Building Draft Code (EERBC) for New Residentail Buildings, Additions and Retrofits. 2003, E gyptian Ministry of Housing, Utilities and Urban Communities; Housing and Building Research Centre.: Cairo.

[14] Shyam, M., Agro-residue-based renewable energy technologies for rural development. Energy for Sustainable Development, 2002. 6(2): p. 37-42.

[15]Pappu, A., M. Saxena, and S.R. Asolekar, Solid wastes generation in India and their recycling potential in building materials. Building and Environment, 2007. 42(6): p. 2311-2320. 
[16]Brandt, A.M., Fibre reinforced cement-based (FRC) composites after over 40 years of development in building and civil engineering. Composite Structures, 2008. 86(1-3): p. 3 9.

[17]EEAA, Egyptian Environemnt Report. 2008, Egyptian Environmental Affairs Agency, Ministry of State of Environmental Affairs: Cairo.

[18]Rahman, M.A., Properties of clay-sand-rice husk ash mixed bricks. International Journal of Cement Composites and Lightweight Concrete, 1987. 9(2): p. 105-108.

[19]Mansour, A., J. Srebric, and B.J. Burley, Development of Straw-cement Composite Sustainable Building Material for Low-cost Housing in Egypt. Journal of Applied Sciences Research, 2007. 3(11): p. 1571-1580.

[20]20. Akmal, T., Recycling Rice-Straw for the manufacure of construction brick, in Arabic. 2005.

[21]ES1991, Egyptian standards 1292/1991 for concrete construction 1991, E gyptian Ministry of Housing, Utilities and urban Communities; Housing and Building Research Centre.: Cairo.

[22]HBRC, Egyptian Code of the basics of the design and implementation of the requirements of building works. 1995, Ministry of Housing, Utilities Research Center of Housing and Construction and Urban Planning: Cairo.

[23]Bruse, M. and H. Fleer, Simulating surface-plant-air interactions inside urban environments with a three dimensional numerical model. Environmental Modelling and Software, 1998. 13(3-4): p. 373-384.

[24]Bruse, M., ENVI-met V3.1, a m icroscale urban climate model, [Online], Available: www.envi-met.com. Accessed 18/3/2009. 2008.

[25]Ali-Toudert, F. and H. Mayer, Numerical study on the effects of aspect ratio and orientation of an urban street canyon on outdoor thermal comfort in hot and dry climate. Building and Environment, 2006. 41(2): p. 94-108.

[26]AutoDesk. [Online], AvateCT2010, at: http://www.autodesk.co.uk/adsk/servlet/mform?validate=no\&siteID=452932\&id=142051 63. Accessed 19/4/2010. 2010 [cited.

[27]ASHRAE, ASHRAE Hand Book of Fundamentals (SI Edition). 2005, Atlanta: American Society of Heating, refrigerating, and Air-Conditioning Engineers Inc.

[28]Oke, T.R., Boundary layer climates. 1987, London: Methuen. 